\title{
Substrate Temperature Effect on the Microstructure and Properties of (Si, Al)/a-C:H Films Prepared through Magnetron Sputtering Deposition
}

\author{
Xiaoqiang Liu, ${ }^{1}$ Junying Hao, ${ }^{2}$ Hu Yang, ${ }^{1}$ Xiuzhou Lin, ${ }^{1}$ and Xianguang Zeng ${ }^{1}$ \\ ${ }^{1}$ Material Corrosion and Protection Key Laboratory of Sichuan Province, Sichuan University of Science and Engineering, \\ Zigong 643000, China \\ ${ }^{2}$ State Key Laboratory of Solid Lubrication, Lanzhou Institute of Chemical Physics, Chinese Academy of Sciences, \\ Lanzhou 730000, China
}

Correspondence should be addressed to Junying Hao; jyhao@licp.cas.cn

Received 11 May 2015; Revised 3 August 2015; Accepted 4 August 2015

Academic Editor: Dan Xia

Copyright (C) 2015 Xiaoqiang Liu et al. This is an open access article distributed under the Creative Commons Attribution License, which permits unrestricted use, distribution, and reproduction in any medium, provided the original work is properly cited.

Hydrogenated amorphous carbon films codoped with $\mathrm{Si}$ and $\mathrm{Al}((\mathrm{Si}, \mathrm{Al}) / \mathrm{a}-\mathrm{C}: \mathrm{H})$ were deposited through radio frequency (RF, $13.56 \mathrm{MHz})$ magnetron sputtering on $\mathrm{Si}(100)$ substrate at different temperatures. The composition and structure of the films were investigated by means of X-ray photoelectron spectroscopy (XPS), TEM, and Raman spectra, respectively. The substrate temperature effect on microstructure and mechanical and tribological properties of the films was studied. A structural transition of the films from nanoparticle containing to fullerene-like was observed. Correspondingly, the mechanical properties of the films also had obvious transition. The tribological results in ambient air showed that high substrate temperature $(>573 \mathrm{~K})$ was disadvantage of wear resistance of the films albeit in favor of formation of ordering carbon clusters. Particularly, the film deposited at temperature of $423 \mathrm{~K}$ had an ultralow friction coefficient of about 0.01 and high wear resistance.

\section{Introduction}

Hydrogenated amorphous carbon (a-C:H) films have been well known for their outstanding mechanical properties such as super-hard (up to $80 \mathrm{GPa}$ ) and excellent tribological performance (friction coefficient lower than 0.01 under vacuum) [1]. However, pure a-C:H films have some intrinsic limitations in application as solid lubricant materials, such as high internal stress, low toughness, and high sensitivity of friction coefficient to humidity. In order to overcome those limitations, doping additional elements has been widely applied to fabricate nanocomposite amorphous carbon films. Among those doped elements, silicon has attracted extensive attention due to its effectiveness in improving thermal stability and enhancing corrosion resistance [2]. In particular, the humidity sensitivity of friction coefficient films can be suppressed by incorporating $\mathrm{Si}$ into a-C:H films based on the forming silicon hydroxides or silicon oxide during friction process [3]. Aluminum has been regarded as one of the most effective elements in relaxing internal stress of a-C:H films [4]. Besides, it was reported that the graphitization of a-C:H films during friction would be enhanced by incorporation of $\mathrm{Al}$, so the friction coefficient can be further reduced [5]. Hence, $\mathrm{Al}$ would be a good candidate as a doping element of a-C:H films. However, incorporation of such metallic element would inevitably cost some hardness of films.

Recently, a mode of duplex-doping was developed to further comprehensively promote the mechanical and tribological properties of carbon-based solid lubricant films. An optimum combination between mechanical and tribological properties of films can be achieved by tailoring the content ratio of codoped elements and the ratio $\mathrm{C} / \mathrm{Me}$ [6] (Me is the metal incorporated into amorphous carbon films). Based on this mode, Wilhelmsson et al. [5] firstly proposed a concept for design of low friction nanocomposite films using $\mathrm{Ti}-\mathrm{Al}-\mathrm{C}$ films as a model system. The $\mathrm{Ti}-\mathrm{Al}-\mathrm{C}$ films exhibited good toughness and low internal stress coupled with low friction. Moreover, it was found in our previous 
TABLE 1: Deposition parameters of the films.

\begin{tabular}{lc}
\hline Parameters & Value \\
\hline Working pressure $(\mathrm{Pa})$ & 1.2 \\
Radio frequency power $(\mathrm{W})$ & 700 \\
Negative substrate bias $(\mathrm{V})$ & -200 \\
Substrate current $(\mathrm{mA})$ & 100 \\
Bias frequency $(\mathrm{KHz})$ & 40 \\
Deposition duration $(\mathrm{min})$ & 90 \\
\hline
\end{tabular}

works that $\mathrm{Si}$ and $\mathrm{Al}$ codoped amorphous carbon films ( $\mathrm{Si}$, $\mathrm{Al}) / \mathrm{a}-\mathrm{C}: \mathrm{H})$ showed superlow friction $(<0.01)$ and superior wear resistance in ambient air with relative humidity of about 40\% [7]. Also, both internal stress and the moisture sensitivity of tribological properties of carbon-based films can be significantly lowered by jointly doping $\mathrm{Si}$ and $\mathrm{Al}$, which was further validated by the works of Zhao et al. [8].

Furthermore, duplex-doping can be in favor of nanostructure construction in amorphous carbon films. Until the present, amorphous carbon films have been deposited with many kinds of nanostructures including nanoparticle containing structure $[5,9,10]$, nanoscale multilayer [11, 12], nanoporous membranes [13], and dual nanostructure [14]. In order to prepare amorphous carbon films with a certain nanostructure through magnetron sputtering deposition methods, there are lots of preparation parameters taken into account, including sputtering power [15], substrate bias voltage [16], and deposition atmosphere [7, 17], which directly influence the growth mode, structure, and properties of amorphous carbon films. In this study, the substrate temperature effect on microstructure and mechanical and tribological properties of the ( $\mathrm{Si}, \mathrm{Al}) / \mathrm{a}-\mathrm{C}: \mathrm{H}$ films was studied. The correlation between the structure and mechanical and tribological properties was discussed.

\section{Experimental Details}

2.1. Films Deposition. The ( $\mathrm{Si}, \mathrm{Al}) / \mathrm{a}-\mathrm{C}: \mathrm{H}$ films were deposited on $\mathrm{Si}$ (100) substrates through sputtering a rectangular target with dimension of $80 \times 240 \mathrm{~mm}^{2}$, consisting of silicon (99.999 wt.\%) and aluminum ( $\geqslant 99.5$ wt.\%) in argon (Ar) and methane $\left(\mathrm{CH}_{4}\right)$ mixture plasma. The exposure area ratio of the $\mathrm{Si}$ and $\mathrm{Al}$ target is $6: 1$. Before the deposition, the substrates were ultrasonically cleaned in alcohol and acetone for $10 \mathrm{~min}$, respectively. The distance between the target and substrate was about $95 \pm 5 \mathrm{~mm}$. The residual pressure of the deposition chamber was evacuated down to $3.0 \times 10^{-4} \mathrm{~Pa}$ and then the substrates were cleaned using Ar ion bombardment at a pressure of $1.2 \mathrm{~Pa}$ and a negative bias voltage of $1000 \mathrm{~V}$ with $70 \%$ duty factor. Subsequently, the substrates were heated to a scheduled temperature and then the $(\mathrm{Si}, \mathrm{Al}) / \mathrm{a}$ $\mathrm{C}: \mathrm{H}$ film was deposited on them. The substrate temperature was controlled at $423 \mathrm{~K}, 473 \mathrm{~K}, 573 \mathrm{~K}, 673 \mathrm{~K}$, and $773 \mathrm{~K}$. The gas flow of methane and argon was $27 \mathrm{sccm}$ and $40 \mathrm{sccm}$, respectively. Other deposition parameters of the films can be found in Table 1.
TABLE 2: Parameters of tribotests.

\begin{tabular}{ll}
\hline Contact load $(\mathrm{N})$ & 2.0 \\
Sliding speed $(\mathrm{m} / \mathrm{s})$ & 0.10 (reciprocating mode) \\
Sliding time $(\mathrm{s})$ & 1800 \\
Relative humidity $(\%)$ & $30-40$ \\
Counter face & Stainless steel ball (AISI 52100), \\
& $\Phi=3 \mathrm{~mm}, \mathrm{HRC}=62, \mathrm{Ra}=0.02 \mu \mathrm{m}$ \\
\hline
\end{tabular}

2.2. Film Characterization. The thickness and morphology of fractured cross section of the films were surveyed by field emission scanning electron microscopy (FESEM, JSM $6701 F)$. The compositions of the films were analyzed by a PHI-5702 X-ray photoelectron spectroscope (XPS) with monochromatic $\mathrm{Al} \mathrm{K \alpha}$ radiation at pass energy of $29.4 \mathrm{eV}$. The residual pressure of the system was lower than $4 \times 10^{-6} \mathrm{~Pa}$. Raman spectra of the films were obtained on a Jobin-Yvon HR 800 Raman microscopy instrument with $532 \mathrm{~nm}$ Ar ion laser and a resolution of $1 \mathrm{~cm}^{-1}$. High resolution transmission electron microscopy was operated on FEI Tecnai G2 F20 FE-TEM at $200 \mathrm{kV}$. The samples for TEM observation were obtained from the as-deposited films on the Si substrate, which mechanically polished and then Ar ion-milled (Gatan 691) at a small angle with respect to the milled surface. The hardness of the films was investigated by a nanoindenter (Hysteron T1950, Hysitron TriboIndenter). The depth of indentation was controlled to $10 \%$ of the film thickness to exclude the influence of the substrate. Five indentation tests were made at different locations of the films. The solid lubricity of the films was evaluated by ball-on-disk method in ambient air. The tribotest parameters can be found in Table 2 . The wear tracks were surveyed using noncontact method on Micro XAM-3D Surface Profile (ADE Phase Shift, USA). Surface morphology of transfer layer sliding against the films was scrutinized by SEM (JSM-5600LV).

\section{Result and Discussion}

3.1. Composition and Microstructure. The composition of the films was surveyed by XPS. The results showed that there was no obvious difference in the composition among the films, as shown in Figure 1. Specifically, oxygen should be concerned with the surface oxidation when the samples were exposed to the air. The composition of the films was almost independent of the growth temperature. On the contrary, the thickness of the films which was detected by FESEM, as shown in Figures 2(a)-2(c), decreased with the increase of growth temperature. Specifically, the deposition rate of the films decreased in contrast with increase of the substrate temperature. The change of deposition rate is consistent with that reported by Shinohara et al. [18]. This kind of phenomenon may be concerned with decrease of sticking coefficient of the chemical species generated in the methane plasma or the increase of density caused by ion bombardment. However, we think the latter is more likely since elemental composition of the films, which depend on the sticking and resputtering of the different chemical species, was almost unchanged with 


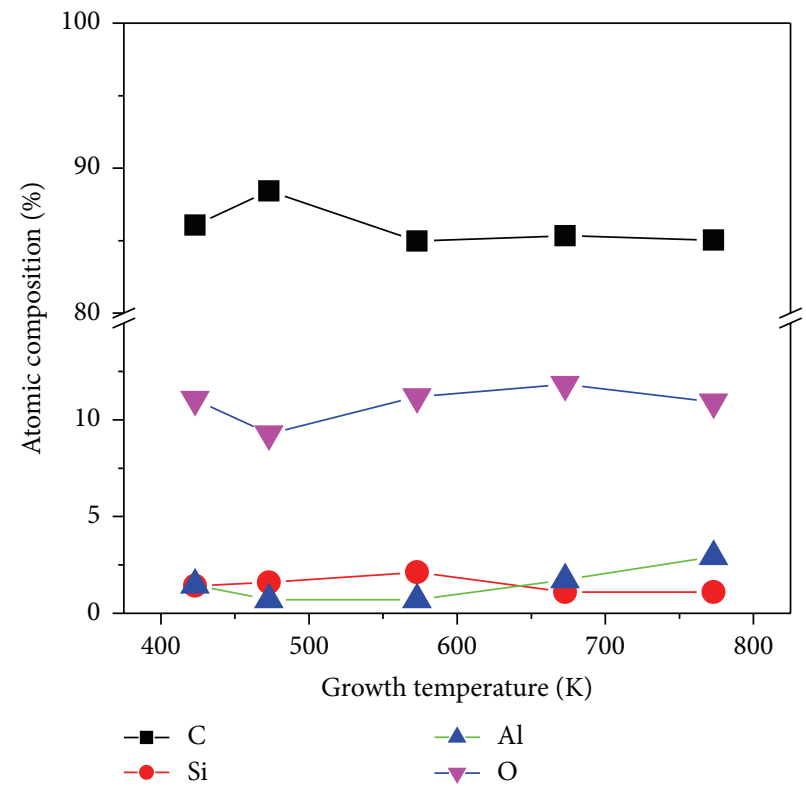

Figure 1: The composition of the films deposited at different substrate temperatures.
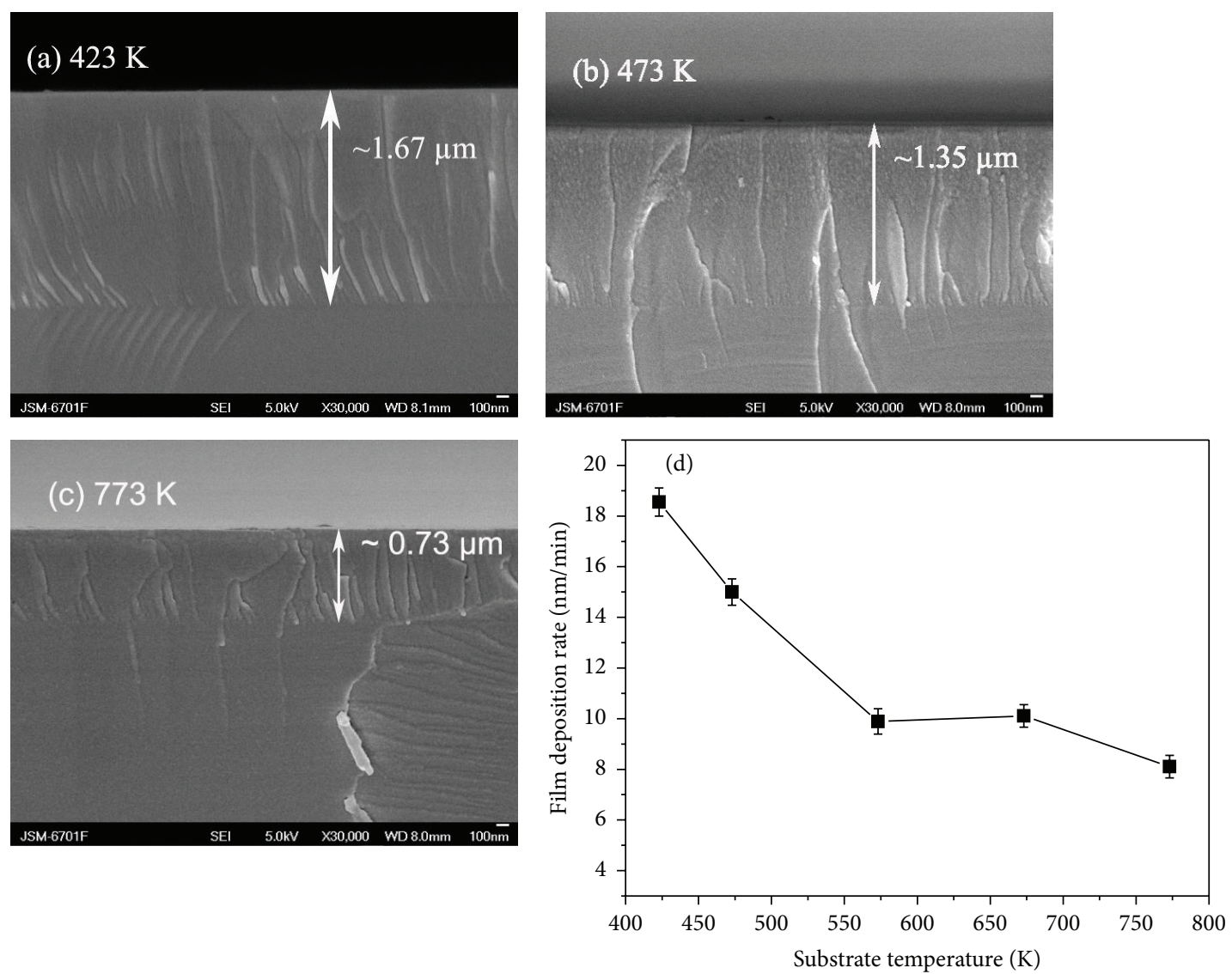

FIGURE 2: $(\mathrm{a}-\mathrm{c}$ ) FESEM images of fractured cross section and (d) total thickness as a function of the substrate temperatures. 


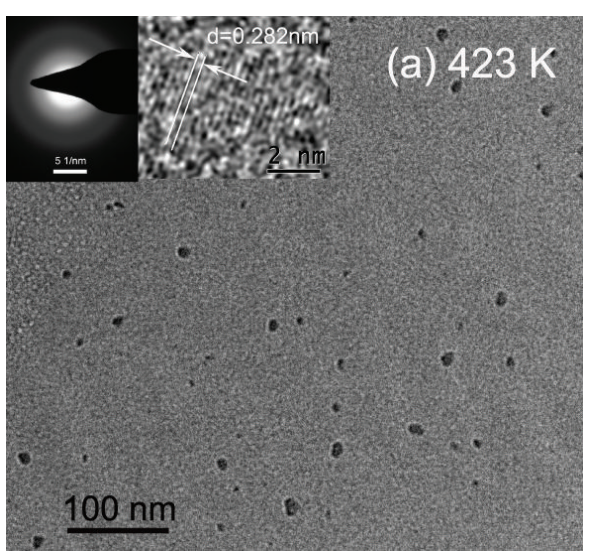

(a)

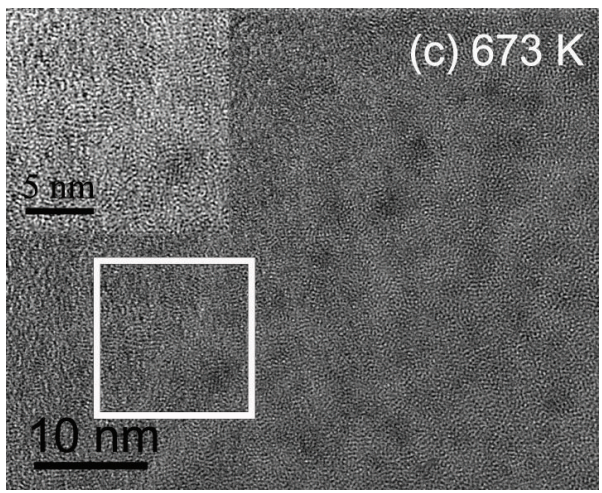

(c)

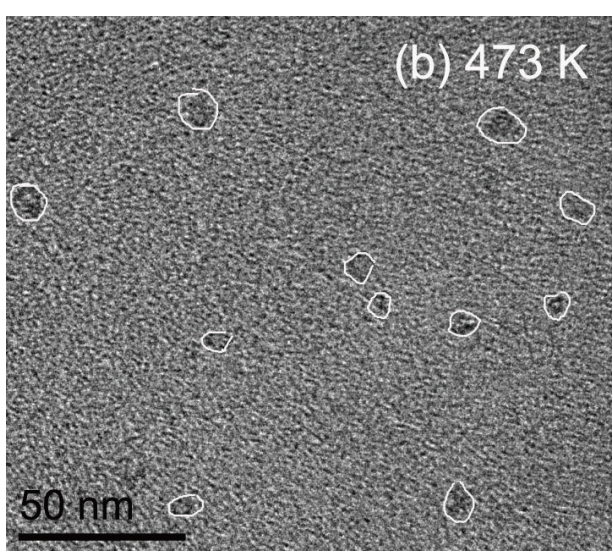

(b)

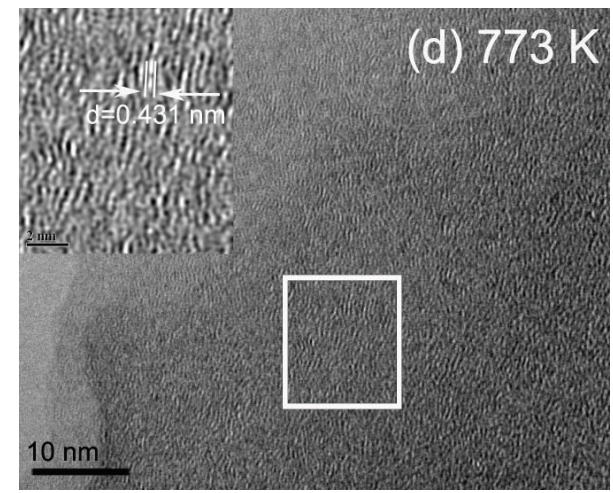

(d)

Figure 3: Plane-view TEM images taken from the bulk of the films deposited at different substrate temperatures (the insets of (a), (c), and (d) are inversely filtered FFT local images of the area marked by white squares): (a) $423 \mathrm{~K}$, (b) $473 \mathrm{~K}$, (c) $673 \mathrm{~K}$, and (d) $773 \mathrm{~K}$.

the increase of substrate temperature, as shown in Figure 1. Additionally, it also could be observed that all of the films are very dense and the interface between the film and substrate gradually became ambiguous, which could be caused by the increase of diffusion of carbon into the silicon substrate with the temperature increase.

The nanostructure evolution of the films as a function of substrate temperatures was investigated by HRTEM. Obviously, the nanostructures of the films were distinct from each other as different substrate temperatures were applied, as shown in Figures 3(a)-3(d). The film deposited at low temperature exhibited a kind of nanoparticle containing structure. The particles mainly consisted of $\mathrm{Si}$ and $\mathrm{Al}$, according to the results of Energy Dispersive X-Ray Spectrum (EDS), and exhibited a lattice space of about $0.282 \mathrm{~nm}$, close to that of Si $\left(d_{201}=0.269 \mathrm{~nm}\right)$. However, the amount of particles was small and they were distributed sparsely in the film, which should be concerned with the low content of doped elements. However, it should be noted that the entire film is amorphous, as suggested by electron diffraction pattern shown in the inset of Figure 3(a). As the substrate was heated up to $673 \mathrm{~K}$, such particles almost did not form. On the other hand, the amorphous carbon matrix of the films gradually graphitized and became relatively ordered with the rising of substrate temperature. As the temperature heightened up to $773 \mathrm{~K}$, as shown in Figure 3(d), the ordering structure was gradually obvious and the film exhibited a structure of parallel curved fringes and the space of the fringes was about $0.431 \mathrm{~nm}$, which is close to the lattice space of the fullerene $\left(d_{112}=\right.$ $0.428 \mathrm{~nm}$ ). Commonly, this kind of structure is usually so called fullerene-like structure [19]. Meanwhile, the film did not contain nanoparticle.

The graphitization of amorphous carbon matrix can be further evidenced by the Raman spectra of the films. As well known, visible Raman spectroscopy is an efficient and nondestructive tool for research of structure information of amorphous carbon matrix in films materials based on carbon. As given in Figures 4(a)-4(e), the Raman spectra of the films mainly consisted of the G peak centered around $1560 \mathrm{~cm}^{-1}$ and D peak (shoulder peak) around $1340 \mathrm{~cm}^{-1}$, which originate from the breathing modes of rings and the bond stretching of all pairs of $\mathrm{sp}^{2}$ atoms in rings and chains $[20,21]$, respectively. It was noted that the D peak became more distinguishable and the "valley" located between the $D$ peak and $G$ peak became deeper with the ascending of the substrate temperature. Additionally, two important parameters of $G$ peak position and the intensity ratio of $D$ and G peaks, $I(\mathrm{D}) / I(\mathrm{G})$, were demonstrated in Figure $4(\mathrm{f})$ as a function of substrate temperatures. As Ferrari and Robertson suggested, the fluctuation of the ratio of $\mathrm{sp}^{3}$ bonded carbon 


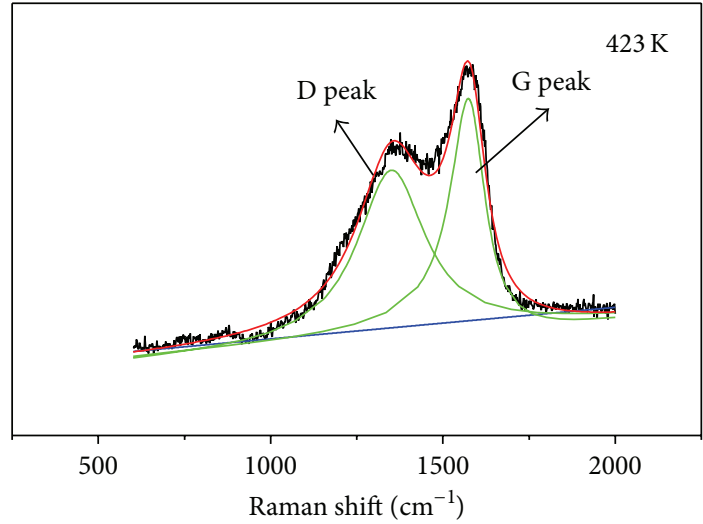

(a)

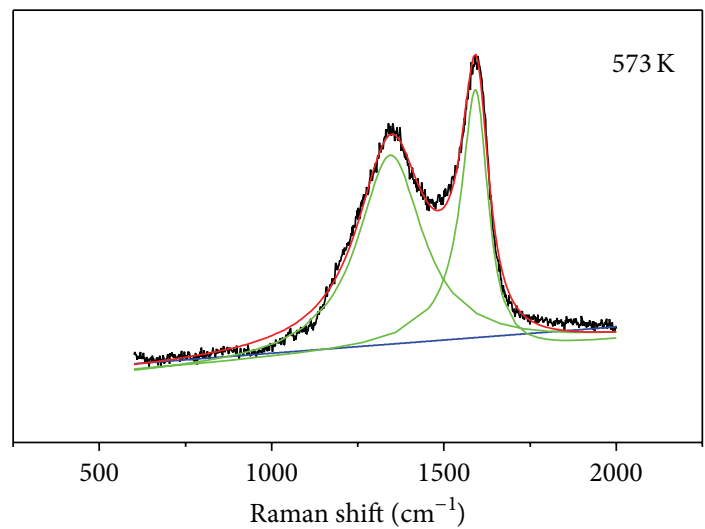

(c)

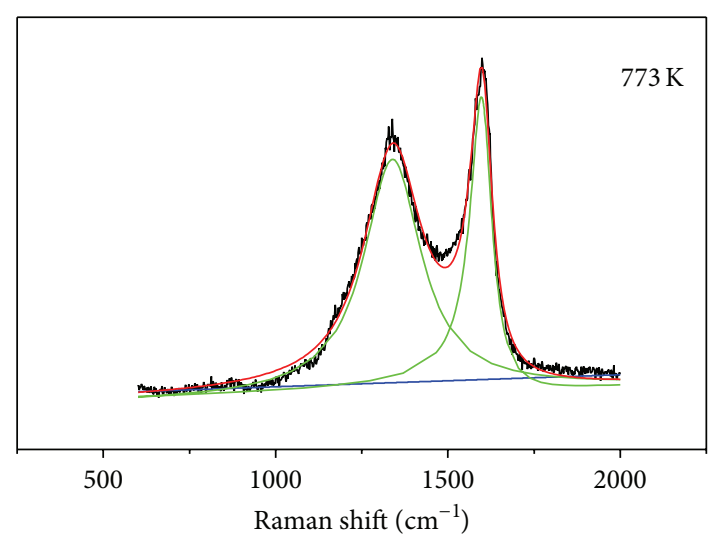

(e)

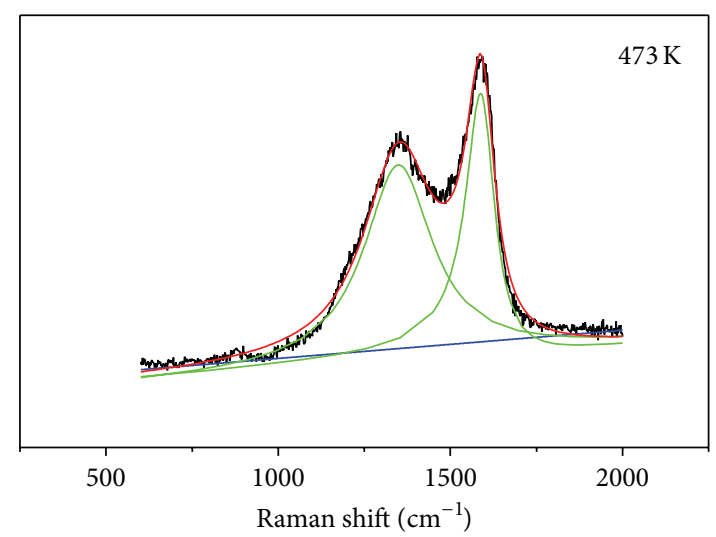

(b)

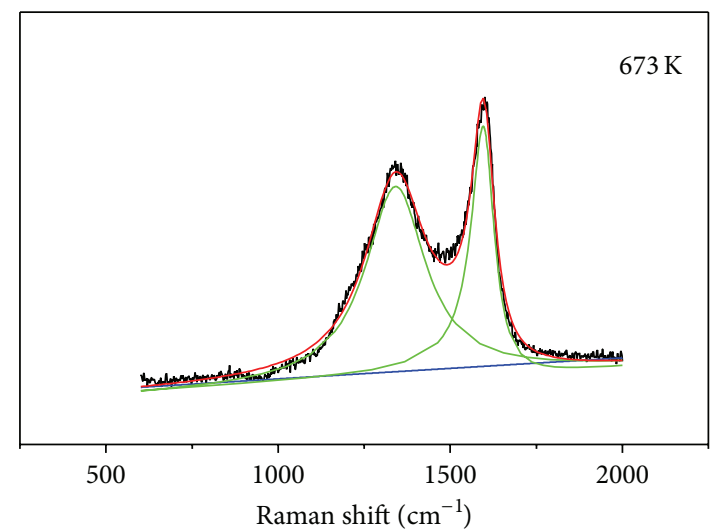

(d)

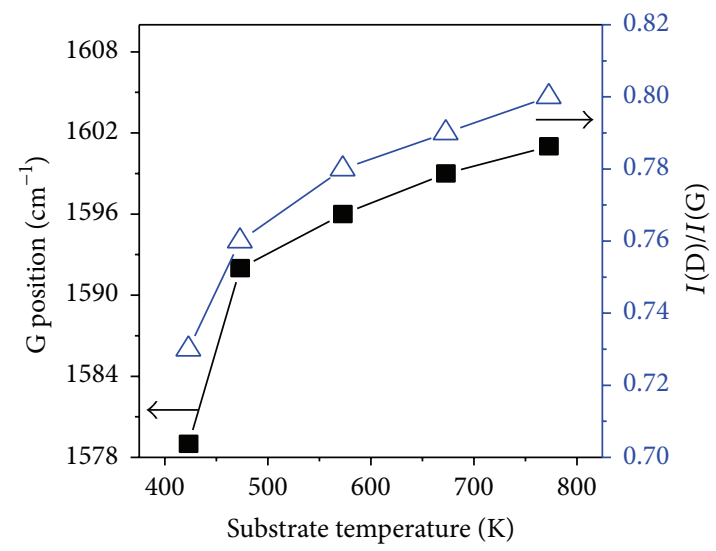

- - G position

$-\triangle-I(\mathrm{D}) / I(\mathrm{G})$

FIGURE 4: (a-e) Raman spectra of the films deposited at different temperatures; (f) G band position and $I(\mathrm{D}) / I(\mathrm{G})$ as a function of substrate temperatures.

and $\mathrm{sp}^{2}$ bonded carbon can be indirectly deduced from the shifting of $\mathrm{G}$ peak position and change of $I(\mathrm{D}) / I(\mathrm{G})$ of visible Raman spectra of amorphous carbon films: the ratio of $\mathrm{sp}^{2} / \mathrm{sp}^{3}$ increases with increase of the two parameters [20,22], and the graphitization degree is proportional to the ratio. Therefore, it was suggested from Figure 4(f) that the ratio of $\mathrm{sp}^{2} / \mathrm{sp}^{3}$ increases with increase of substrate temperature.
In other words, the carbon matrix gradually graphitized as the substrate temperature heightened, which was in good agreement with the observation of the TEM.

3.2. Mechanical and Tribological Properties. The hardness of the films was determined through an indentation method. Figure 5 shows the hardness for films deposited at different 


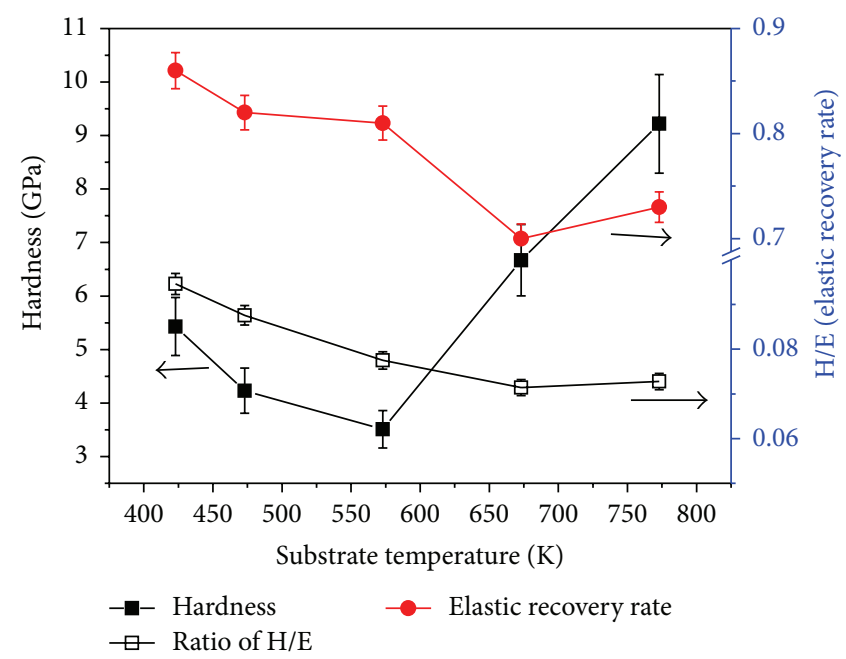

FIgURE 5: The microhardness, ratio of $\mathrm{H} / \mathrm{E}$, and elastic recovery rate of the films as a function of substrate temperatures.

TABLE 3: Duration of reaching the lowest friction coefficient $(\boldsymbol{\mu})$ of the films.

\begin{tabular}{lccccc}
\hline Substrate temperature/K & 423 & 473 & 573 & 673 & 773 \\
\hline Lowest $\boldsymbol{\mu}$ & 0.01 & 0.03 & 0.06 & 0.035 & 0.04 \\
Duration/second & 1700 & 1300 & 190 & 166 & 30 \\
\hline
\end{tabular}

substrate temperatures. All the films are relatively soft since their hardness is not beyond $10 \mathrm{GPa}$. As the temperature rises from $423 \mathrm{~K}$ to $573 \mathrm{~K}$, the hardness of the films did not change significantly, slightly decreasing from $5.4 \mathrm{GPa}$ to 3.5 . With further increase of substrate temperature up to $773 \mathrm{~K}$, the hardness obviously increased from $3.5 \mathrm{GPa}$ to $9.2 \mathrm{GPa}$. Such enhancement of hardness should be attributed to the unique fullerene-like structure $[23,24]$. However, the ratio of $\mathrm{H} / \mathrm{E}$ and elastic recovery rate (E, elastic modulus), which are important prediction parameters of cracking resistance or toughness of hard films or coatings [7, 25-27], degraded with the increase of substrate temperature. Namely, high substrate temperature should be disadvantage of the toughness and wear resistance of the films.

The results of dry-sliding tribotest showed that the film deposited at temperature of $423 \mathrm{~K}$ had a very low and stable friction coefficient of about 0.01 and it increased to about 0.034 as the substrate temperature ascended to $473 \mathrm{~K}$, as given in Figure 6. As substrate temperature heightened up to $573 \mathrm{~K}$ and above, the friction coefficient of the films was about 0.065 , as shown in the inset of Figure 6, but it lasted a short sliding duration. Meanwhile, it is noted that the duration of reaching the lowest friction coefficient decreases with increase of substrate temperature, as listed in Table 3. Also, the wear resistance of the films was reflected by the wear depth of the sliding tracks, as demonstrated in Figures 7(a)7 (c). In comparison to the films deposited at $423 \mathrm{~K}$ and $473 \mathrm{~K}$, the depth of film at $623 \mathrm{~K}$ was significantly larger than the thickness of the film. This meant that the film was easily worn through post-dry-sliding duration of about 900 seconds. Thus, it can be found that the wear resistance of the films

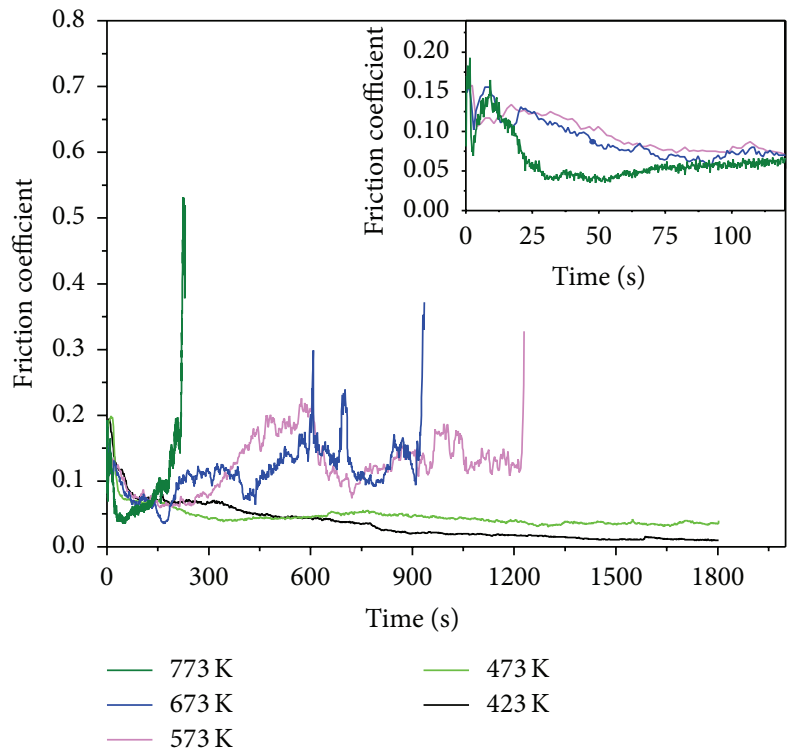

FIGURE 6: Friction curves of the films deposited at different substrate temperatures (the inset displays three friction curves with duration of 120 seconds).

degenerated with the increase of the substrate temperature. Besides, the negative effect caused from increase of substrate temperature on wear resistance was more significant than on the friction coefficient of films.

Mechanically, the decrease of cracking resistance or toughness was indicated by the $\mathrm{H} / \mathrm{E}$ and elastic recovery rate of the films, and transfer layers could be responsible for the degeneration of tribological properties of the films with increase of substrate temperature. Figures $7(\mathrm{~d})-7(\mathrm{f})$ show the SEM micrographs of transfer layers on counter faces sliding against the films deposited at different substrate temperatures. It has been proved that a continuous and dense transfer layer has positive effects on the high lubrication performance in the ambient air due to the much lower 

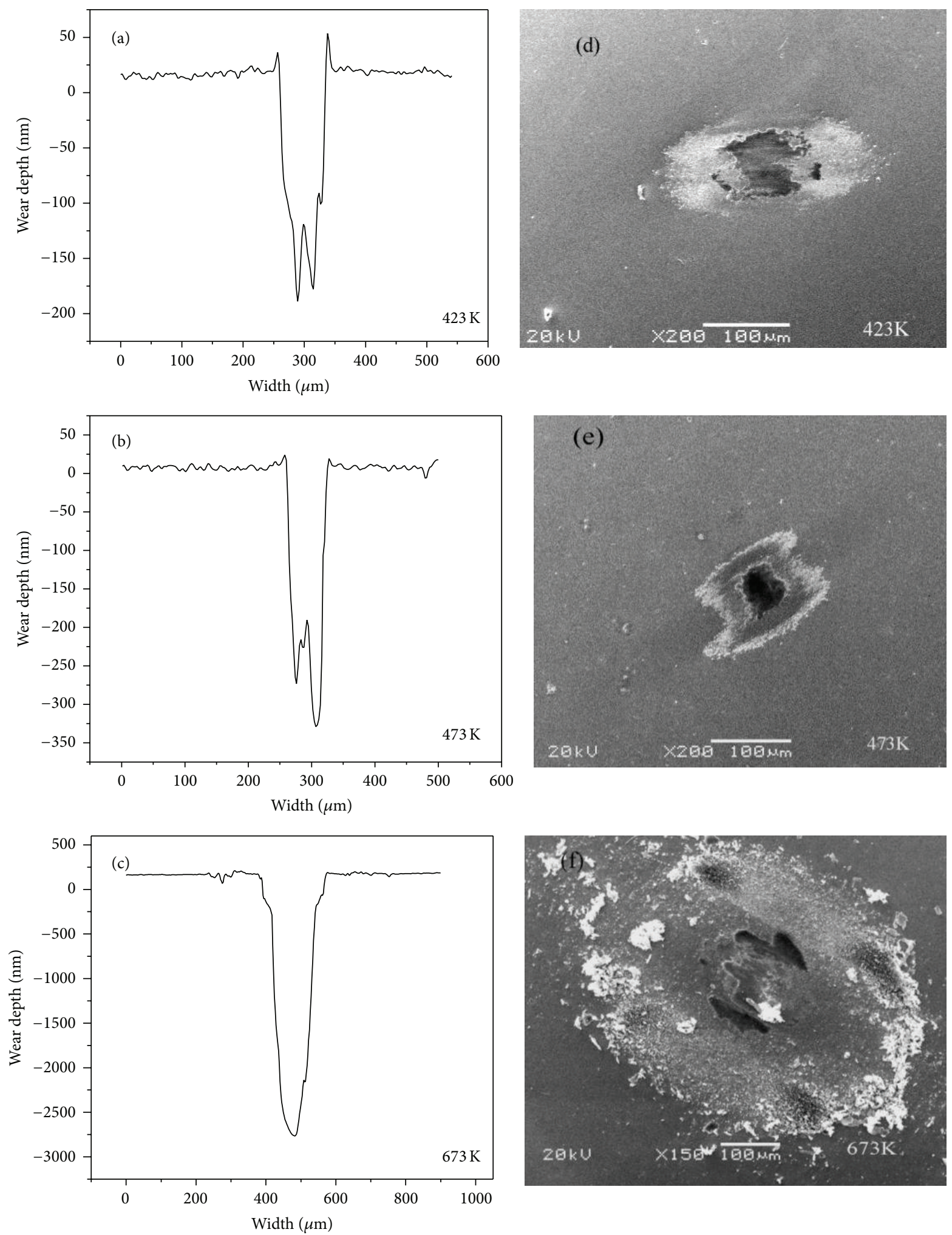

FIGURE 7: Cross-sectional profiles $(\mathrm{a}-\mathrm{c}$ ) of the wear tracks (after sliding time of $1800 \mathrm{~s}$ ) and corresponding transfer layers (d-f) on the counter faces produced from the dry sliding of the films deposited at different substrate temperatures. 
interfacial shear stress between the two carbon surfaces [8, 28 ], and triboinduced graphitization of sliding interface is beneficial to the reduction of friction coefficient $[5,28,29]$. As a result of increase of graphitization level which is previously verified by the TEM and Raman spectra of the films, the duration of reaching the lowest friction coefficient decreases with increase of substrate temperature. However, because of the low toughness which is indicated by the ratio $\mathrm{H} / \mathrm{E}$, the films deposited at high temperature did not last a long duration of low friction state and the films were easily worn through, regardless of formation of transfer layer on counter faces.

\section{Conclusions}

( $\mathrm{Si}, \mathrm{Al}$ )/a-C:H films were deposited at different substrate temperatures. The dependence of the microstructure, hardness, and tribological properties of the films on growth temperature was studied. The results of HRTEM and Raman spectra revealed that the films underwent significant microstructure evolution from particle containing to fullerene-like structure as the growth temperature increased from $423 \mathrm{~K}$ to $773 \mathrm{~K}$. The graphitization level of the films increased with the substrate temperature, leading to shortening of the duration of reaching the lowest friction coefficient. However, the wear resistance of the films still significantly degenerated since the reduction of toughness of the films, even though the lubricity of the films was not seriously damaged when high substrate temperature was applied.

\section{Conflict of Interests}

The authors declare that there is no conflict of interests regarding the publication of this paper.

\section{Acknowledgments}

The authors are grateful to financial support of State Key Laboratory of Solid Lubrication (Grant LSL-1303), Sichuan University of Science and Engineering (Grant 2013RC01), Material Corrosion and Protection Key Laboratory of Sichuan Province (Grant 2015CL14), the National Natural Science Foundation of China (Grant 51375471), and 973 projects (2013CB632302) of the Ministry of Science and Technology of China.

\section{References}

[1] J. Robertson, "Diamond-like amorphous carbon," Materials Science and Engineering: R: Reports, vol. 37, no. 4-6, pp. 129-282, 2002.

[2] G. A. Abbas, P. Papakonstantinou, J. A. McLaughlin, T. D. M. Weijers-Dall, R. G. Elliman, and J. Filik, "Hydrogen softening and optical transparency in Si-incorporated hydrogenated amorphous carbon films," Journal of Applied Physics, vol. 98, no. 10, Article ID 103505, 2005.

[3] F. Zhao, H. X. Li, L. Ji et al., "Structural, mechanical and tribological characterizations of a-C: $\mathrm{H}$ : Si films prepared by a hybrid PECVD and sputtering technique," Journal of Physics D: Applied Physics, vol. 42, no. 16, Article ID 165407, 2009.

[4] W. Dai and A. Wang, "Deposition and properties of Alcontaining diamond-like carbon films by a hybrid ion beam sources," Journal of Alloys and Compounds, vol. 509, no. 13, pp. 4626-4631, 2011.

[5] O. Wilhelmsson, M. Ràsander, M. Carlsson et al., "Design of nanocomposite low-friction coatings," Advanced Functional Materials, vol. 17, no. 10, pp. 1611-1616, 2007.

[6] J. Musil, P. Novák, R. Čerstvý, and Z. Soukup, “Tribological and mechanical properties of nanocrystalline-TiC/a-C nanocomposite thin films," Journal of Vacuum Science \& Technology A, vol. 28, no. 2, pp. 244-249, 2010.

[7] X. Liu, J. Hao, J. Yang et al., "Preparation of superior lubricious amorphous carbon films co-doped by silicon and aluminum," Journal of Applied Physics, vol. 110, no. 5, Article ID 053507, 2011.

[8] F. Zhao, H. Li, L. Ji, Y. Wang, H. Zhou, and J. Chen, “Ti-DLC films with superior friction performance," Diamond and Related Materials, vol. 19, no. 4, pp. 342-349, 2010.

[9] X. Q. Liu, J. Yang, J. Y. Hao, and W. M. Liu, "Microstructure and properties of nc-TiC/a-C:H films deposited by radio frequency reactive sputtering," Materials Science and Technology, vol. 27, no. 11, pp. 1669-1673, 2011.

[10] A. A. Onoprienko, N. I. Danilenko, and I. A. Kossko, "Structure evolution on annealing of copper-doped carbon film," Thin Solid Films, vol. 515, no. 17, pp. 6672-6675, 2007.

[11] F. J. Li, S. Zhang, J. Kong, Y. Zhang, and W. Zhang, "Multilayer DLC coatings via alternating bias during magnetron sputtering," Thin Solid Films, vol. 519, no. 15, pp. 4910-4916, 2011.

[12] M. Stueber, H. Holleck, H. Leiste, K. Seemann, S. Ulrich, and C. Ziebert, "Concepts for the design of advanced nanoscale PVD multilayer protective thin films," Journal of Alloys and Compounds, vol. 483, no. 1-2, pp. 321-333, 2009.

[13] S. Karan, S. Samitsu, X. Peng, K. Kurashima, and I. Ichinose, "Ultrafast viscous permeation of organic solvents through diamond-like carbon nanosheets," Science, vol. 335, no. 6067, pp. 444-447, 2012.

[14] X. Liu, J. Yang, J. Hao, J. Zheng, Q. Gong, and W. Liu, "A nearfrictionless and extremely elastic hydrogenated amorphous carbon film with self-assembled dual nanostructure," Advanced Materials, vol. 24, no. 34, pp. 4614-4617, 2012.

[15] Y. T. Pei, C. Q. Chen, K. P. Shaha et al., "Microstructural control of $\mathrm{TiC} / \mathrm{a}-\mathrm{C}$ nanocomposite coatings with pulsed magnetron sputtering," Acta Materialia, vol. 56, no. 4, pp. 696-709, 2008.

[16] W. M. Liu, X. Pang, J. Hao, P. Wang, and Y. Xia, "Effects of bias voltage on structure and properties of TiAl-doped a-C:H films prepared by magnetron sputtering," Surface and Interface Analysis, vol. 43, no. 3, pp. 677-682, 2011.

[17] W. Gulbiński, S. Mathur, H. Shen, T. Suszko, A. Gilewicz, and B. Warcholiński, "Evaluation of phase, composition, microstructure and properties in TiC/a-C:H thin films deposited by magnetron sputtering," Applied Surface Science, vol. 239, no. 34, pp. 302-310, 2005.

[18] M. Shinohara, K. Cho, Y. Matsuda et al., "Substrate temperature effects on amorphous carbon film growth, investigated by infrared spectroscopy in multiple internal reflection geometry," Journal of Vacuum Science \& Technology A, vol. 27, no. 4, pp. 813-817, 2009.

[19] I. Alexandrou, H.-J. Scheibe, C. J. Kiely, A. J. Papworth, G. A. J. Amaratunga, and B. Schultrich, "Carbon films with an $\mathrm{sp}^{2}$ network structure," Physical Review B: Condensed Matter and Materials Physics, vol. 60, no. 15, pp. 10903-10907, 1999. 
[20] A. C. Ferrari and J. Robertson, "Interpretation of Raman spectra of disordered and amorphous carbon," Physical Review B, vol. 61, no. 20, pp. 14095-14107, 2000.

[21] A. C. Ferrari, "Raman spectroscopy of graphene and graphite: disorder, electron-phonon coupling, doping and nonadiabatic effects," Solid State Communications, vol. 143, no. 1-2, pp. 47-57, 2007.

[22] G. Irmer and A. Dorner-Reisel, "Micro-Raman studies on DLC coatings," Advanced Engineering Materials, vol. 7, no. 8, pp. 694705, 2005.

[23] P. Wang, X. Wang, B. Zhang, and W. Liu, "Structural, mechanical and tribological behavior of fullerene-like carbon film," Thin Solid Films, vol. 518, no. 21, pp. 5938-5943, 2010.

[24] P. Wang, X. Wang, W. Liu, and J. Zhang, "Growth and structure of hydrogenated carbon films containing fullerene-like structure," Journal of Physics D, vol. 41, no. 8, Article ID 085401, 2008.

[25] C. A. Charitidis, "Nanomechanical and nanotribological properties of carbon-based thin films: a review," International Journal of Refractory Metals \& Hard Materials, vol. 28, no. 1, pp. 5170, 2010.

[26] J. Musil and M. Jirout, "Toughness of hard nanostructured ceramic thin films," Surface \& Coatings Technology, vol. 201, no. 9-11, pp. 5148-5152, 2007.

[27] A. Leyland and A. Matthews, "On the significance of the $H / E$ ratio in wear control: a nanocomposite coating approach to optimised tribological behaviour," Wear, vol. 246, no. 1-2, pp. $1-11,2000$.

[28] X. Liu, J. Yang, J. Hao, J. Zheng, Q. Gong, and W. Liu, "Microstructure, mechanical and tribological properties of $\mathrm{Si}$ and $\mathrm{Al}$ co-doped hydrogenated amorphous carbon films deposited at various bias voltages," Surface and Coatings Technology, vol. 206, no. 19-20, pp. 4119-4125, 2012.

[29] A. P. Merkle, A. Erdemir, O. L. Eryilmaz, J. A. Johnson, and L. D. Marks, "In situ TEM studies of tribo-induced bonding modifications in near-frictionless carbon films," Carbon, vol. 48, no. 3, pp. 587-591, 2010. 

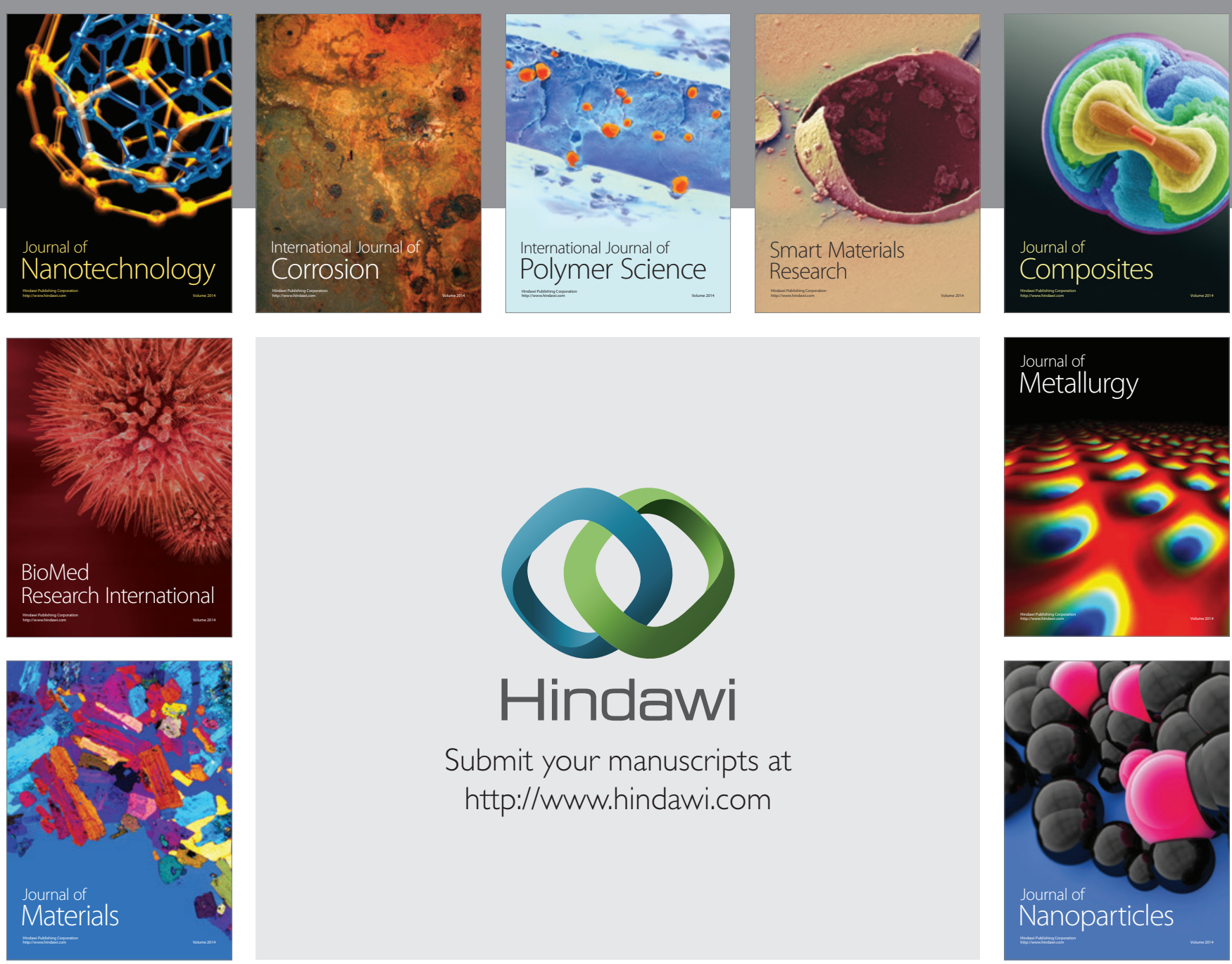

Submit your manuscripts at http://www.hindawi.com
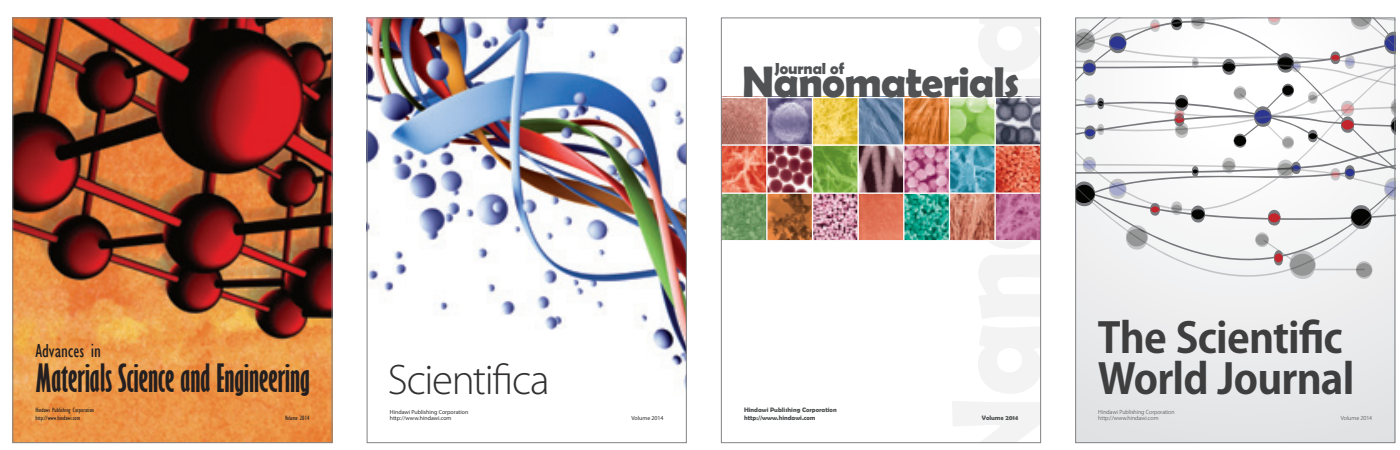

\section{The Scientific World Journal}
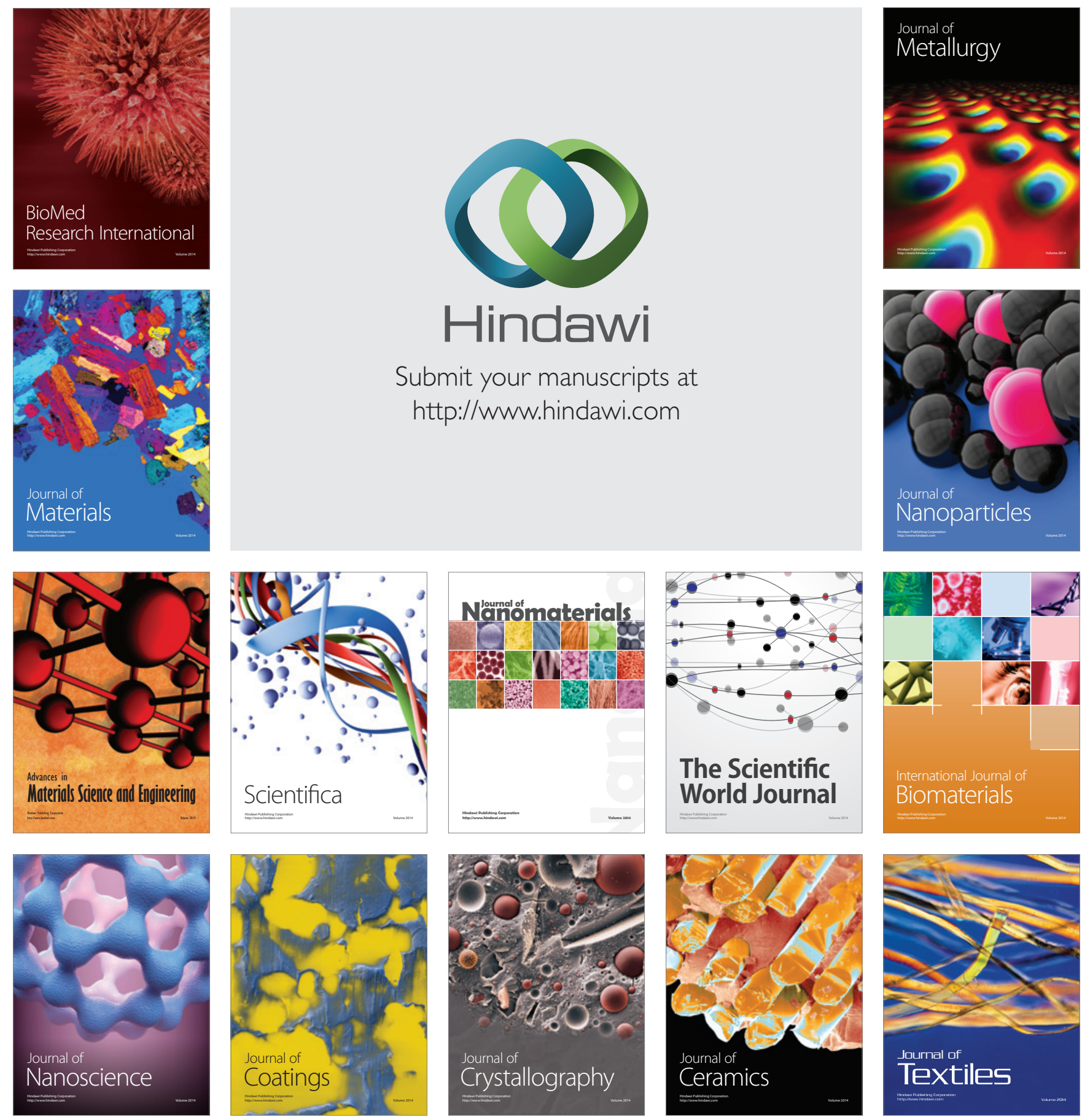